\title{
Thrombocytopenia in hypertensive disorder of pregnancy: maternal and perinatal outcome
}

\author{
Varsha Deshmukh, Aulia Nasrin, SN Gadappa \\ Corresponding author: Dr. Aulia Nasrin, Chief Resident, Dept of OBGY, Government Medical \\ College, Aurangabad, India; Email : aulianasrinkgmc09@gmail.com
}

Distributed under Attribution-Non Commercial - Share Alike 4.0 International (CC BY-NC-SA 4.0)

\begin{abstract}
Background: Pregnancy induced hypertension (PIH) is one of the most common causes of both maternal and neonatal morbidity. A variety of haematological abnormalities may occur in women with PIH of which thrombocytopenia is the most common. Objectives: This study was done to estimate the incidence of thrombocytopenia in pregnant women diagnosed with PIH and to correlate the severity of PIH with the degree of thrombocytopenia. The maternal and perinatal outcome was analyzed according to the severity of thrombocytopenia in hypertensive disorders of pregnancy. Material and methods: This is a prospective observational study conducted in the Department of OBGY, GMCH Aurangabad during a period of 2 years (September 2017 to October 2019) in women who were admitted in labor room or ANC ward with diagnosis of hypertensive disorder of pregnancy with thrombocytopenia. Data from case files was collected, compiled, and analyzed. Results: In the present study, preeclampsia - nonsevere (20\%) and severe (50\%), accounted for most of the cases followed by eclampsia (13\%) and gestational hypertension (17\%). In the 100 cases, mild thrombocytopenia $(25 \%)$, moderate thrombocytopenia $(62 \%)$, severe thrombocytopenia (13\%), were encountered. Poor maternal outcome was seen in $30.6 \%$ cases due to postpartum haemorrhage, DIC, abruption and two maternal deaths in severe thrombocytopenia group. The maternal outcome was significantly associated with severity of thrombocytopenia of patients $(p=0.017)$. The severity of thrombocytopenia was significantly associated with perinatal outcome of patients $(\mathrm{p}=0.038)$. Out of 100 newborns, there were 16 IUFD and 13 early neonatal deaths. IUFD accounted for $38.4 \%$ in severe thrombocytopenia group and $12 \%$ in mild thrombocytopenia group $(\mathrm{p}=0.064)$. Conclusions: Thrombocytopenia in hypertensive disorder of pregnancy increases maternal and perinatal morbidity and mortality. Careful follow up during and after pregnancy is recommended.
\end{abstract}

Keywords: Thrombocytopenia, preeclampsia, eclampsia.

Thrombocytopenia in pregnancy may be physiological or may be pathological. The cause for physiological decrease in platelet count is multifactorial and is related to hemodilution, increased platelet consumption and increased platelet aggregation due to increase level of thromboxane A2. Physiological thrombocytopenia is most common in 3rd trimester of pregnancy ${ }^{1,2}$. The cause of thrombocytopenia is pathological in hypertensive disorders of pregnancy like preeclampsia, eclampsia, pre-eclampsia superimposed on chronic hypertension and associated complications like HELLP syndrome and acute fatty liver disease.
Thrombocytopenia causes unnecessary and invasive additional testing and caesarean deliveries. The evaluation and treatment of this disorder can be expensive and distressing to patient. Thrombocytopenia is associated with adverse perinatal outcome. Therefore this study was done with aim of finding the incidence of thrombocytopenia at our institute, estimating the proportion of cases with hypertensive disorder of pregnancy with thrombocytopenia, and correlation of maternal and perinatal outcome in hypertensive disorder of pregnancy with the severity of thrombocytopenia.

Received: $13^{\text {th }}$ January 2021, Peer review completed: $6^{\text {th }}$ March 2021, Accepted: $7^{\text {th }}$ March 2021.

Deshmukh V, Nasrin A, Gadappa SN. Thrombocytopenia in hypertensive disorder of pregnancy: maternal and perinatal outcome. The New Indian Journal of OBGYN. 2022; 8(2): 233 - 39. 
The New Indian Journal of OBGYN. 2021 (January-June);8(2)

\section{Methodology}

This study is a prospective observation study conducted in department of obstetrics and gynaecology, GMC Aurangabad during September 2017 to October 2019 after obtaining ethical committee approval. 100 antenatal women were selected for the study.

Inclusion criteria was woman with hypertensive disorders of pregnancy patient with $>30$ weeks of gestation with platelets count $<150,000 / \mathrm{mm}^{3}$. They were grouped as - a) Mild thrombocytopenia $100,000-150,000 / \mathrm{mm}^{3}$, b) Moderate thrombocytopenia $50,000-100,000 / \mathrm{mm}^{3}$ and c) Severe thrombocytopenia $<50,000 / \mathrm{mm}^{3}$.

Exclusion criteria was woman with history of bleeding disorder, previous pregnancy with history of thrombocytopenia, or medical disease associated with pregnancy such as SLE, hepatitis, HIV, infection, dengue and presence of splenomegaly or history of drug intake like aspirin.

After obtaining written informed consent, relevant data was compiled by a common proforma that included socio-demographic characteristics of mothers (age, parity socioeconomic status according to modified Kuppuswamy scale), obstetric history, family history and other

\begin{tabular}{l} 
Table 1: Distribution of pati \\
\hline Types of hypertensive \\
disorder of pregnancy \\
\hline Gestational hypertension \\
Nonsevere preeclampsia \\
Severe preeclampsia \\
Eclampsia \\
Total \\
\hline
\end{tabular}
comorbid conditions. Presenting complaints were noted. General and systemic examination in mother at presentation was done. The gestational age, presentation, amount of liquor and FHS was noted. Participants were observed throughout the labour. Intrapartum patients were monitored with partograph and CTG. Decision regarding mode of delivery (vaginal delivery and lower segment caesarean section) was taken by consultants. All women were followed up to delivery and postpartum period. Patients were monitored for complications like postpartum haemorrhage ( $\mathrm{PPH}$, abruption, disseminated intravascular coagulation (DIC), acute renal failure (ARF), eclampsia HELLP syndrome, cerebrovascular accident (CVA), pulmonary edema, acute respiratory distress syndrome (ARDS), sepsis, multiple organ dysfunction syndrome (MODS), ventilator support and death during labour, delivery and post delivery. The neonates were followed up to early neonatal period in terms of birth weight, Apgar score at one and five minutes, preterm birth, low birth weight, intrauterine fetal growth restriction (IUGR), NICU (neonatal intensive care unit) admission, complication and early neonatal death.

Statistical analysis: The data was compiled in MS-Excel sheet and for analysis of this data; SPSS (Statistical package for social sciences) version 25 th was used. Chi-square test was applied to see association between severity of thrombocytopenia and perinatal and maternal outcome. Also ANOVA was used to check significance difference between platelet count in severity of pregnancy induced hypertension. The significance level of this test was checked at 0.05 . Student t-test was used for doing comparison of platelet count in severe preeclampsia, non severe preeclampsia and eclampsia.

\section{Results}

The study included 20 cases of nonsevere preeclampsia, 


\begin{tabular}{llllllll} 
Table 3: showing the association between thrombocytopenia and mode of delivery \\
$\begin{array}{llll}\text { Modes of } \\
\text { delivery }\end{array}$ & $\begin{array}{l}\text { Mild } \\
\text { thrombocytopenia } \\
\mathbf{N = 2 5}\end{array}$ & $\begin{array}{l}\text { Moderate } \\
\text { thrombocytopenia } \\
\mathbf{N}=\mathbf{6 2}\end{array}$ & $\begin{array}{l}\text { Severe } \\
\text { thrombocytopenia } \\
\mathbf{N = 1 3}\end{array}$ & Percentage \\
\hline PTVD & 10 & $25 \%$ & 23 & $57.5 \%$ & 7 & $17.5 \%$ & 40 \\
FTVD & 7 & - & 22 & - & 0 & - & 29 \\
Instrumental delivery & 0 & $0 \%$ & 1 & $50 \%$ & 1 & $50 \%$ & 2 \\
Preterm LSCS & 1 & $25 \%$ & 2 & $50 \%$ & 1 & $25 \%$ & 4 \\
Term LSCS & 7 & $68 \%$ & 4 & $16 \%$ & 4 & $16 \%$ & 25 \\
Total & 25 & $25 \%$ & 62 & $62 \%$ & 13 & $13 \%$ & 100 \\
\hline PTVD - Preterm vaginal delivery, FTVD - Full term vaginal delivery, LSCS - Lower segment caesarean \\
section. P $<0.032$ (Significant), Chi square value -14.07.
\end{tabular}

severe thrombocytopenia group was $35.26 \pm 2.06$ wks, $37.03 \pm$ $2.03 \mathrm{wks}$, and $34.38 \pm 2.05 \mathrm{wks}$ respectively.

The severity of thrombocytopenia was significantly associated with mode of delivery of patients $(p=0.032) \quad($ table 3$) .5$ out of 13 patients $(38.46 \%)$ of severe thrombocytopenia

\begin{tabular}{|c|c|c|c|c|c|c|c|}
\hline \multirow{2}{*}{$\begin{array}{l}\text { Maternal } \\
\text { complications }\end{array}$} & \multicolumn{2}{|c|}{$\begin{array}{l}\text { Mild } \\
\text { thrombocytopenia } \\
\mathrm{N}=25\end{array}$} & \multicolumn{2}{|c|}{$\begin{array}{l}\text { Moderate } \\
\text { thrombocytopenia } \\
\mathrm{N}=62\end{array}$} & \multicolumn{2}{|c|}{$\begin{array}{l}\text { Severe } \\
\text { thrombocytopenia } \\
\mathrm{N}=13\end{array}$} & \multirow{2}{*}{$\begin{array}{l}\text { Percentage } \\
22 \%\end{array}$} \\
\hline & 5 & $22.72 \%$ & 13 & $59.09 \%$ & 4 & $18.18 \%$ & \\
\hline DIC & 2 & $18.18 \%$ & 7 & $63.63 \%$ & 2 & $18.18 \%$ & $11 \%$ \\
\hline Abruption & 2 & $25.0 \%$ & 5 & $62.5 \%$ & 1 & $12.5 \%$ & $8 \%$ \\
\hline Pulmonary oedema & 0 & $0 \%$ & 3 & $75 \%$ & 1 & $25 \%$ & $4 \%$ \\
\hline Sepsis & 1 & $25 \%$ & 1 & $25 \%$ & 2 & $50 \%$ & $4 \%$ \\
\hline Acute kidney injury & 0 & $0 \%$ & 1 & $50 \%$ & 1 & $50 \%$ & $2 \%$ \\
\hline MODS & 1 & $50 \%$ & 0 & $0 \%$ & 1 & $50 \%$ & $2 \%$ \\
\hline Cavernous sinus thrombosis & 0 & $0 \%$ & 1 & $100 \%$ & 0 & $0 \%$ & $1 \%$ \\
\hline Others & 2 & $33.33 \%$ & 4 & $66.67 \%$ & 0 & $0 \%$ & $6 \%$ \\
\hline No complication & 11 & $28.95 \%$ & 27 & $71.05 \%$ & 0 & $0 \%$ & $38 \%$ \\
\hline Maternal death & 1 & $50 \%$ & 0 & $0 \%$ & 1 & $50 \%$ & $2 \%$ \\
\hline
\end{tabular}
underwent LSCS. 16 out of 62 patients $(25.80 \%)$ of moderate thrombocytopenia underwent LSCS. The most common indication for full term LSCS was previous LSCS with hypertensive disorder of pregnancy, and second most common indication was fetal distress.

8.30. The mean platelet count at admission in gestational hypertension, nonsevere pre-eclampsia, severe preeclampsia, and eclampsia was 90,518.52 $\pm 31,581.8 / \mathrm{mm}^{3}, 85,181.82 \pm$ $24,169.9 / \mathrm{mm}^{3}, 79,871.79 \pm 24,438.25 / \mathrm{mm}^{3}$ and $79,416.67$ $\pm 26,613.25 / \mathrm{mm}^{3}$ respectively.
All patients of severe thrombocytopenia developed complication during intrapartum and postpartum period. Out of 25 patients of mild thrombocytopenia, 5 patients had $\mathrm{PPH}$, while out of 13 patients of severe thrombocytopenia, 4 patients had PPH. As severity of thrombocytopenia

\begin{tabular}{|c|c|c|c|c|c|c|c|}
\hline \multirow{2}{*}{$\begin{array}{l}\text { Perinatal outcomes } \\
\text { Healthy baby }\end{array}$} & \multicolumn{2}{|c|}{$\begin{array}{l}\text { Mild thrombocytopenia } \\
\text { N=25 }\end{array}$} & \multicolumn{2}{|c|}{$\begin{array}{l}\text { Moderate thrombocytopenia } \\
\mathrm{N}=62\end{array}$} & \multicolumn{2}{|c|}{$\begin{array}{l}\text { Severe thrombocytopenia } \\
\mathrm{N}=13\end{array}$} & \multirow{2}{*}{$\begin{array}{l}\text { Percentage } \\
39 \%(\mathrm{p}<0.046)\end{array}$} \\
\hline & 14 & $35.9 \%$ & 23 & $58.98 \%$ & 2 & $5.12 \%$ & \\
\hline Preterm & 2 & $15.38 \%$ & 9 & $69.23 \%$ & 2 & $15.38 \%$ & $13 \%$ \\
\hline NICU admission & 2 & $16.67 \%$ & 9 & $75 \%$ & 1 & $8.33 \%$ & $12 \%$ \\
\hline IUGR & 1 & $14.28 \%$ & 4 & $57.14 \%$ & 2 & $28.58 \%$ & $7 \%$ \\
\hline IUFD & 3 & $18.75 \%$ & 8 & $50 \%$ & 5 & $31.25 \%$ & $16 \%(\mathrm{p}<0.064)$ \\
\hline Early neonatal death & 3 & $23.07 \%$ & 9 & $69.23 \%$ & 1 & $7.69 \%$ & $13 \%$ \\
\hline \multicolumn{8}{|l|}{ Apgar at $5 \mathrm{~min}$} \\
\hline$<7$ & 8 & $17.02 \%$ & 34 & $72.34 \%$ & 5 & $10.64 \%$ & $47 \%(\mathrm{p}<0.038)$ \\
\hline$>7$ & 14 & $37.84 \%$ & 20 & $54.05 \%$ & 3 & $8.10 \%$ & $37 \%$ \\
\hline Birth asphyxia & 2 & $22.22 \%$ & 6 & $66.67 \%$ & 1 & $11.11 \%$ & $9 \%$ \\
\hline RDS & 1 & $16.67 \%$ & 3 & $50 \%$ & 2 & $33.33 \%$ & $6 \%$ \\
\hline Pneumonia & 0 & $0 \%$ & 4 & $100 \%$ & 0 & $0 \%$ & $4 \%$ \\
\hline Pathological jaundice & 3 & $50 \%$ & 3 & $50 \%$ & 0 & $0 \%$ & $6 \%$ \\
\hline Other & 2 & $28.58 \%$ & 3 & $42.85 \%$ & 2 & $28.57 \%$ & $7 \%$ \\
\hline
\end{tabular}

NICU - Neonatal intensive care unit, IUGR - Intrauterine growth restriction, IUFD - Intrauterine foetal death, LBW - Low birth weight, RDS Respiratory distress syndrome

Table 2 shows the demographic profile of the patients. The mean age was $23.60 \pm 3.78$ years in our study. Unbooked patients were $77 \%$ in the study as our hospital is a tertiary referral centre. The study shows $57 \%$ multigravida patients. The mean gestational age in mild moderate and increases, the number of blood products supplied to patients also increased. The maternal outcome were significantly associated with severity of thrombocytopenia of patients $(p=0.016)$. Both the maternal deaths were seen in severe thrombocytopenia group (table 4). The severity of 
thrombocytopenia was significantly associated with adverse perinatal outcome of patients $(p=0.038)$ (table 5). In mild thrombocytopenia, 6 out of 25 babies had poor perinatal outcome. In severe thrombocytopenia group, 6 out of 13 babies had poor perinatal outcome. This shows, as severity of thrombocytopenia increases perinatal morbidity and mortality also increases.

\section{Discussion}

One of the most common medical complications of pregnancy is PIH. It is more common in the developing countries than in the developed countries 3,4 . Thrombocytopenia occurring during pregnancy creates a diagnostic as well as a management problem. Asymptomatic thrombocytopenia is observed near term in about 5\% of normal pregnancies and in about $15 \%$ of women with preeclampsia ${ }^{5}$. A variety of haematological abnormalities may occur in women with PIH of which thrombocytopenia is the most common abnormality ${ }^{6}$.

A total of 100 patients of hypertensive disorder of pregnancy with thrombocytopenia constituted the study group. Among the study group 17 patients had gestational hypertension, 20 patients had nonsevere preeclampsia, 50 patients had severe preeclampsia and 13 patients had eclampsia. As this study was conducted at tertiary care hospital which is referral center for PHC and other peripheral hospitals, almost $50 \%$ patients presented with severe preeclampsia on admission. This centre has the facility for ICU admission and ventilator support, NICU admission of babies and platelet transfusion. This explains the high number of unbooked patients in the study $(77 \%)$.

It was found that severity of HDP and thrombocytopenia observed are closely correlated, which indicate that thrombocytopenia is directly proportional to severity of HDP. Significant association was noted between decreasing platelet count and worsening spectrum of disease. Similar trends were observed by Ellora Devi et al ?. Thrombocytopenia in PIH probably occurs as a result of immunologically mediated process or more likely due to increased platelet deposition at the site of endothelial damage and activation of coagulation system in small vessels. Out of all the haematological changes that occur in preeclampsia and eclampsia, thrombocytopenia is the most common haematological abnormality found.

In the present study, mean age of patients $23.60 \pm 3.78$ years. Early age of marriage and pregnancy in our country explains this finding. Similar findings were noted by Kolluru et al ${ }^{8}$.
There was no significant association of thrombocytopenia and period of gestation as $p$ value was not significant $(p=0.443)$. Out of 100 women with HDP pregnancy of 63 women could not be prolonged because of severe preeclampsia /eclampsia or severe thrombocytopenia or fetal complications (63 out of 100). 44 women were preterm at presentation. The remaining 37 women were term. Riaz et al ${ }^{9}$ also had similar findings.

The mode of delivery in our study shows that (44/100) $44 \%$ had preterm delivery (40 normal vaginal and 4 by LSCS). The indications of LSCS for preterm LSCS in this study were as follows: 2 for IUGR with evidence of fetal hypoxia in doppler, 1 had features of imminent eclampsia and 1 had abruption. The LSCS maternal and perinatal outcome was good.

The other 56 patients were term and 29 participants out of 56 delivered vaginally (71\%), 2 had instrumental delivery and 25 needed LSCS (29\%). The vaginal delivery rate was $71 \%$ and LSCS rate was $29 \%$ in our study. The most common indication of LSCS in this term group of patients in our study was previous LSCS with HDP, and second most common indication was fetal distress. Pacher $\mathrm{J}$ et al ${ }^{10}$ also had similar rates in their study on HDP with thrombocytopenia.

In our study we found that life threatening complications of HDP were significantly more in women with severe thrombocytopenia than with mild thrombocytopenia. As severity of thrombocytopenia increases, maternal morbidity and mortality increases and number of blood products supplied to patients also found to be increased ( $p=0.017$ ). In preeclampsia, defective placental vascular remodelling around mid second trimester of pregnancy with the second round of trophoblastic invasion into the deciduas results in inadequate placental perfusion. The hypoxic placenta then releases various placental factors such as soluble vascular endothelial growth factor receptor-1 (sVEGFR-1), which then binds vascular endothelial growth factor (VEGF) and placental growth factor (PGF), causing endothelial cell and placental dysfunction by preventing them from binding endothelial cell receptors. This results in increased platelet activation and aggregation leading to low platelet count, haemolysis and hepatic injury ${ }^{11,12}$.

We noticed that 5 out of $25(20 \%)$ patients in mild thrombocytopenia group had $\mathrm{PPH}$ whereas 4 out of 13 (30.6\%) developed PPH in patients of HDP with severe thrombocytopenia. Another 2 patients developed DIC in severe thrombocytopenia group. This reflects that thrombocytopenia may prove as an additive risk factor for 
PPH. PPH was the commonest maternal complication in our study (22\%) followed by DIC (11\%) followed by abruption (8\%). All patients of severe thrombocytopenia developed complication during intrapartum and postpartum period. All complicated cases were promptly managed with a multidisciplinary approach and were successfully treated. However 2\% patient who developed multi-organ dysfunction syndrome died in the severe thrombocytopenia group.

Pulmonary edema is another life threatening complication of preeclampsia which develops as a result of endothelial damage in pulmonary vasculature. $7.6 \%$ of women with moderate and severe thrombocytopenia in our study developed pulmonary edema ( $p$ value 0.04 ) which is similar to the incidence by Shazly et al ${ }^{13}$. No patient with mild thrombocytopenia developed pulmonary edema in our study.

Kidneys also have the brunt of HDP. The hallmark of renal lesion in preeclampsia is glomerular endotheliosis. In our study the incidence of ARF was $2 \%$ in women with moderate and severe thrombocytopenia. No patient with mild thrombocytopenia developed kidney injury. Celik et al ${ }^{12}$ reported still higher incidence of ARF (36\%) probably because of the fact that he conducted the study in women who already had full blown HELLP.

There were 2 maternal deaths in our study. The causes of death were - 1) Pulmonary embolism with severe preeclampsia with severe anaemia with severe thrombocytopenia with febrile illness post LSCS day 6 patient with abruption placenta and 2) Septicemia with shock with acute kidney injury with severe pre-eclampsia with abruptio-placenta with severe thrombocytopenia. This finding is similar to a study conducted in Pakistan that reported maternal death rate of $6.23 \%$ among women with severe thrombocytopenia with hypertension ${ }^{14}$.

The maternal morbidity and mortality in HDP is directly corelated with the severity of thrombocytopenia ${ }^{15}$. Maternal complications of HDP include the HELLP syndrome (hemolyisis, elevated liver enzymes, low platelets), pulmonary edema, acute liver/renal failure, disseminated intravascular coagulopathy, adult respiratory distress syndrome, sepsis and liver hemorrhage ${ }^{16}$. Low platelet counts in HDP have been suggested as a simple indicator for the risk for the severity of HDP. The observed low counts may result from platelet activation and subsequent consumption that may be more pronounced in $\mathrm{HDP}^{17}$. The maternal outcome was significantly affected by the severity of thrombocytopenia in hypertensive disorders of pregnancy $(\mathrm{p}=0.017)$. Approximately $30 \%$ of all maternal near-miss events will be due to pregnancy hypertension ${ }^{18}$ with nearmiss events complicating about $420 / 100,000$ deliveries ${ }^{19}$. As with most causes of maternal death, avoidable delays in triage, transport and treatment contribute to a majority of HDP related maternal deaths ${ }^{20}$.

The severity of thrombocytopenia was significantly associated with unfavourable perinatal outcome of patients $(\mathrm{p}=0.038)$. Out of 100 newborns, there were 16 IUFD and 13 early neonatal deaths $(\mathrm{p}=0.038)$. In the severe thrombocytopenia group (5/13)38.4\% patients presented with IUFD whereas $(3 / 25) 12 \%$ patients with IUFD presented in mild thrombocytopenia $(\mathrm{p}=0.064)$. Out of the remaining 84 babies, 7 babies had IUGR, 31 babies were preterm birth with morbidities and 13 babies had early neonatal deaths. Hypertensive disorder of pregnancy leads to placental insufficiency and eventually IUGR, which result in poor fetal outcome. In our study fetal complications like growth restriction and NICU admissions were significantly higher in severe thrombocytopenic group (44\%) as compared to mild and moderate thrombocytopenic group (7.6\%).

Out of 100 babies, 62 babies were LBW (weight $<2.5$ $\mathrm{kg}$ ). There were 4 extremely low birth weight babies and 6 were very low birth weight babies in our study. There was a statistical significant association between severity of thrombocytopenia and birth weight of babies of patients $(\mathrm{p}=0.001)$. As the severity of thrombocytopenia increases, birth weight decreases. Von Dadelszen $\mathrm{P}$ et al ${ }^{21}$ reported higher incidence of neonatal complications in patients with preeclampsia and thrombocytopenia (19.61\%). Due to their association with iatrogenic prematurity and foetal growth restriction, the HDP are identifiable risk factors for newborn morbidity (e.g., respiratory distress and neonatal hypoglycaemia) ${ }^{22}$.

\section{Conclusion}

Preeclampsia is a multiorgan disease which imposes significant risk to the maternal and fetal life. It behaves as a double edged sword. In such cases platelet count proves to be a good predictor of development of severe complications of preeclampsia. Thus, it is of great help to investigate women with platelet count to predict severity as early as possible, so as to intervene timely and prevent complications. Early detection and early referral of pregnant women with hypertensive disorder, to have easily available and affordable laboratory testing; frequent maternal and fetal monitoring; increase accessibility of antihypertensive and anticonvulsive drugs; increase preparation for neonatal resuscitation; and, improving quality of neonatal intensive care units can significantly improve the outcome. 
Conflict of interest: None. Disclaimer: Nil.

\section{References}

1. Donimath KV, Sambrani AM, Rathod PM. A Study of association of thrombocytopenia with pregnancy induced hypertension. IJRCOG. 2016 Mar; 5(3): 808-12.

2. Sujata N, Shinde PJ, Verma A, Ghatge RM, Gupta S, Inamdar AA. Assessment of platelets count and platelets indices in pregnancy induced hypertension. Int $\mathrm{J}$ Adv Res. 2017; 5(2): 2067-71.

3. Khodary M, Salem H. Low platelet count as a predictor of complications in severe preeclampsia managed conservatively. Anatol J Obstet Gynecol. 2012; 2: 1.

4. Singhal S, Deepika, Anshu, Nanda S. Maternal and Perinatal Outcome in Severe Pre-eclampsia and Eclampsia. JSAFOG. 2009; 1(3): 25-8.

5. Naljayan MV, Karumanchi SA. New developments in the pathogenesis of Preeclampsia. Advances in chronic kidney disease. 2013 May; 20(3): 265-70.

6. GBD 2013 Risk Factors Collaborators, Forouzanfar MH, Alexander L, Anderson HR, Bachman VF, Biryukov S, et al. Global, regional, and national comparative risk assessment of 79 behavioral environmental and occupational, and metabolic risks or clusters of risks in 188 countries, 1990-2013: a systematic analysis for the Global Burden of Disease Study 2013. Lancet. 2015 Dec 5; 386(10010): 2287-323.

7. Devi E. Combination of Platelet \& Uric Acid Estimation Can Predict Severity of PIH Better. Int J Pharm Bio Sci. 2012 July; 3(3):1039-45.

8. Kolluru V, Harika RY, Kaul R. Maternal and perinatal outcome associated with pregnancy induced hypertension. Int J Reprod Contracept Obstet Gynecol. 2016 Oct; 5(10): 3367-71.

9. Riaz S, Habib S, Jabeen A. Frequency of maternal mortality and morbidity in pregnancy induced hypertension. J Ayub Med Coll Abbottabad. 2011; 23(4); 61-3.

10. Pacher J, Brix E, Lehner R. The mode of delivery in patients with preeclampsia at term subject to elective or emergency Cesarean section. Arch Gynecol Obstet. 2014; 289: 263-7.

11. 11. Steinborn A, Rebmann V, Scharf A, Sohn C, Grosse-Wilde H. Soluble HLA-DR levels in the maternal circulation of normal and pathologic pregnancy. Am J Obstet Gynecol. 2003; 188: 473-9.
12. Agatisa PK, Ness RB, Roberts JM, Costantino JP, Kuller LH, McLaughlin MK. Impairment of endothelial function in women with a history of preeclampsia: an indicator of cardiovascular risk. Am J Physiol Heart Circ Physiol. 2004; 286: H1389-93.

13. 13. Shazly S, Ali M, Abdel Badee A, Alsokkary A, Khodary M, Salem H. Low platelet count as a predictor of complications in severe preeclampsia managed conservatively. Anatol J Obstet Gynecol. 2012; 2: 1.

14. Celik C, Gezginc K, Altintepe L, et al. Results of the pregnancies with HELLP syndrome. Ren Fail. 2003; 25(4): 613-8.

15. Hossain N, Shah N, Khan N, Lata S, Khan NH. Maternal and perinatal outcome of hypertensive disorders of pregnancy at a tertiary care hospital. J Dow Univ Health Sci Karachi. 2011; 5(1): 12-6.

16. Mtali YS, Lyimo MA, Luzzatto L, Massawe SN. Hypertensive disorders of pregnancy are associated with an inflammatory state: evidence from hematological findings and cytokine levels. BMC Pregnancy Childbirth. 2019 Jul 9; 19(1): 237.

17. Duley L. The global impact of pre-eclampsia and eclampsia. Semin Perinatol. 2009; 33(3):130-7.

18. Al Sheeha MA, Alaboudi RS, Alghasham MA, Iqbal J, Adam I. Platelet count and platelet indices in women with preeclampsia. Vasc Health Risk Manag. 2016;12: 477-80.

19. Macey MG, Bevan S, Alam S, Verghese L, Agrawal S, Beski S, et al. Platelet activation and endogenous thrombin potential in pre-eclampsia. Thromb Res. 2010; 125(3): e 76-e81.

20. Lotufo FA, Parpinelli MA, Haddad SM. Applying the new concept of maternal near-miss in an intensive care unit. Clinics (Sao Paulo). 2012; 67(3): 225-30.

21. Naderi T, Foroodnia S, Omidi S. Incidence and correlates of maternal near miss in Southeast Iran. Int J Reprod Med. 2015; 2015 : 914713.

22. Tuncalp O, Hindin MJ, Souza JP. The prevalence of maternal near miss: a systematic review. BJOG. 2012 May; 119(6): 653-61.

23. Khowaja AR, Mitton C, Bryan S. Economic evaluation of community level interventions for pre-eclampsia (CLIP) in South Asian and African countries: a study protocol. Implement Sci. 2015; 10: 76.

24. Von Dadelszen P, Magee L. presenting deaths due to hypertensive disorders of pregnancy. Best practice and Research clinical Obstetrics and Gynaecology. 2016 Oct; 36: 83-103. 
The New Indian Journal of OBGYN. 2021 (January-June);8(2)

25. Kassebaum NJ, Bertozzi-Villa A, Coggeshall MS. Global, regional, and national levels and causes of maternal mortality during 1990--2013: a systematic analysis for the Global Burden of Disease Study 2013. Lancet. 2014 September 13; 384(9947): 980-1004.

Varsha Deshmukh ${ }^{1}$, Aulia Nasrin ${ }^{2}$, SN Gadappa ${ }^{3}$
${ }^{1}$ Professor, Dept of OBGY, Government Medical College \& Cancer Hospital, Aurangabad, India; ${ }^{2}$ Chief Resident, Dept of OBGY, Government Medical College, Aurangabad, India; ${ }^{3}$ Professor and HOD, Dept of OBGY, Government Medical College, Aurangabad, India. 